\title{
Fuzzy Self Tuning Of De Position Control Based On Labview
}

\author{
Fakhraldeen Hamid Ali \\ Sura Nawfal Abd Alrazaaq
}

Computer Engineering Department- University of Mosul - Iraq

Email: fhali310@yahoo.com

\begin{abstract}
This paper investigates the effect of quantization gain factors, at the input side, and the scaling gain, at the output side, of a fuzzy controller. A fuzzy control system is designed with two main parts: a basic fuzzy controller (BFC) which produces the output control signal and supervisor fuzzy controllers (SFCs) to continuously adjust, on-line, the I/O scaling or gain factors of the (BFC) in order to improve its performance against different dynamic operating conditions. The designed self tuning controller is used to position control of a DC motor with un known parameters according to the feed back inputs, a tracking error (e) and change of error $(\Delta \mathrm{e})$, based on the proposed fuzzy rules. The system implementation and tests are carried out using LabVIEW software ( V8.2 ) with a data acquisition card type (NI PCI6251) from National Semiconductors to achieve real time measurements.
\end{abstract}

Keywords: self-tuning, fuzzy controller, position control, scaling gain, LabVIEW .

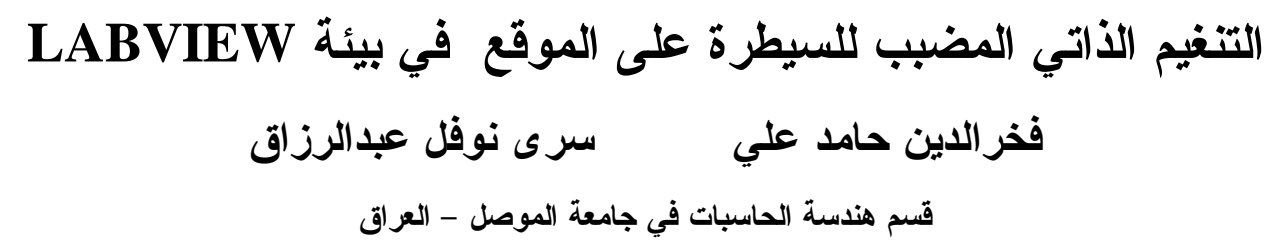

\footnotetext{
الخلاصة

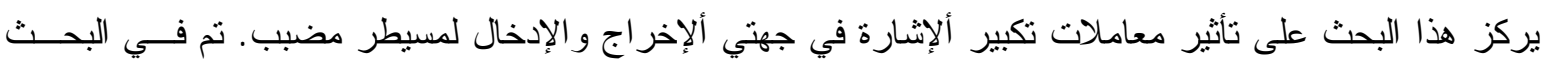

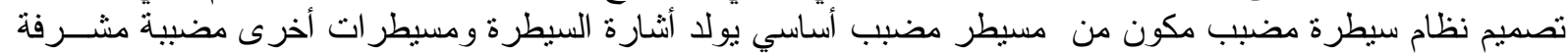

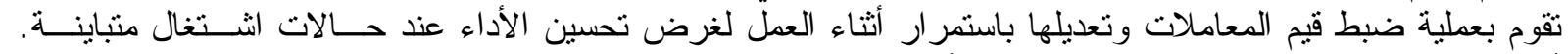

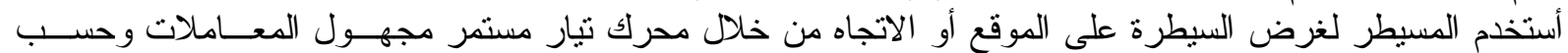

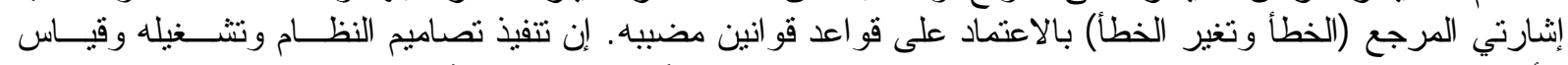

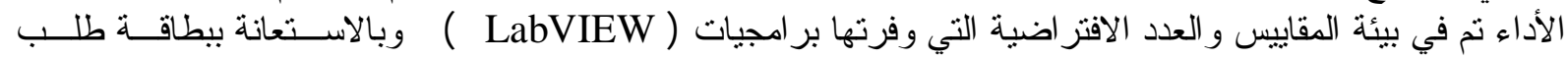
البيانات ( NI PCI-6251 ).
} 


\section{1- Introduction}

Fuzzy control is becoming one of the brightness and most rapidly ascending stars in the galaxy of intelligent control [1]. This is because it offers a simpler, quicker and more reliable solution that is clear advantages over conventional technique. One of its main advantages is that no mathematical modeling is required since the controller rules are especially based on the knowledge of system behavior and experience of the control engineer [2] . Although fuzzy logic allows for the creation of simple control algorithms, the tuning of fuzzy controllers is relatively difficult and a sophisticated procedure is required to overcome plant parameter variations or changes in operating condition. This is due to the large number of parameters that can be altered off-line or on-line to improve its performance and robustness. These include membership functions, rule base and scaling factors. Each scaling factor is responsible for mapping an input or output to the UOD (Universe Of Discourse). Selection of these factors andlor tuning them are crucial which in many cases are set based on some training data or through trial and error procedure [3]. They have large effects on the performance, therefore adjustment of these parameters is the most commonly adopted method for tuning fuzzy controllers [4][5][6]. However, there is no systematic method to find the proper factors yet. Many researchers used different techniques to tune them. In [6] neural networks are used for tuning the output factor only and genetic algorithms are utilized in [7] to tune I/O factors, but these techniques need a number of iterations to achieve the desired performance and this is not applicable in real time implementation. In the present work a fuzzy technique is used for automatic tuning of the input and output factors.

In general, drives do not need a fuzzy chip (like microcontrollers, FPGA) to control them, but, instead a moderate PC, data acquisition card (DAQ) with a well tuned algorithm are sufficient enough to control many drive systems [8]. Also the major obstacle in using text based programming languages as a tool to implement the intelligent control algorithms, is the difficulty to modify the control algorithm even for a slight change in the drive system. On the other hand, a graphical programming language has the flexibility, reusability and user friendly interfacing.

LabVIEW Virtual Instruments (or VI) software can be used with a wide range of applications especially in control field [9]. The LabVIEW combined with built in tools being designed specifically for test, measurement, and control, together with a facility for interfacing with real world signals is adopted for implementing the current system. Therefore variations in the control system can be observed in real time and the user commands can also be accepted during the process.

\section{2- Control system structure}

The structure of the DC servo motor control system with fixed factors fuzzy controller is shown in Fig.1. This controller have been designed with two inputs, position error between desired angle and actual angle $E(k)$, and change of position error $\Delta E(k)$, Where :

$\mathrm{E}(\mathrm{k})=\mathrm{Ge} \mathrm{e}(\mathrm{k})$

$\Delta \mathrm{E}(\mathrm{k})=\mathrm{Gec} \Delta \mathrm{e}(\mathrm{k})$

The output $u(k)$ of the fuzzy controller is the control signal to the motor that is sent via DAQ card ( analogue output channel 21), and the current position is continuously read in real time by the designed VI-program via the DAQ's analogue input (channel 36) as a feedback 
signal from the potentiometer. The output can be expressed as a function (F) of the two inputs:

$\mathrm{U}(\mathrm{k})=\mathrm{F}(\mathrm{E}(\mathrm{k}), \Delta \mathrm{E}(\mathrm{k})) \mathrm{Gu}$

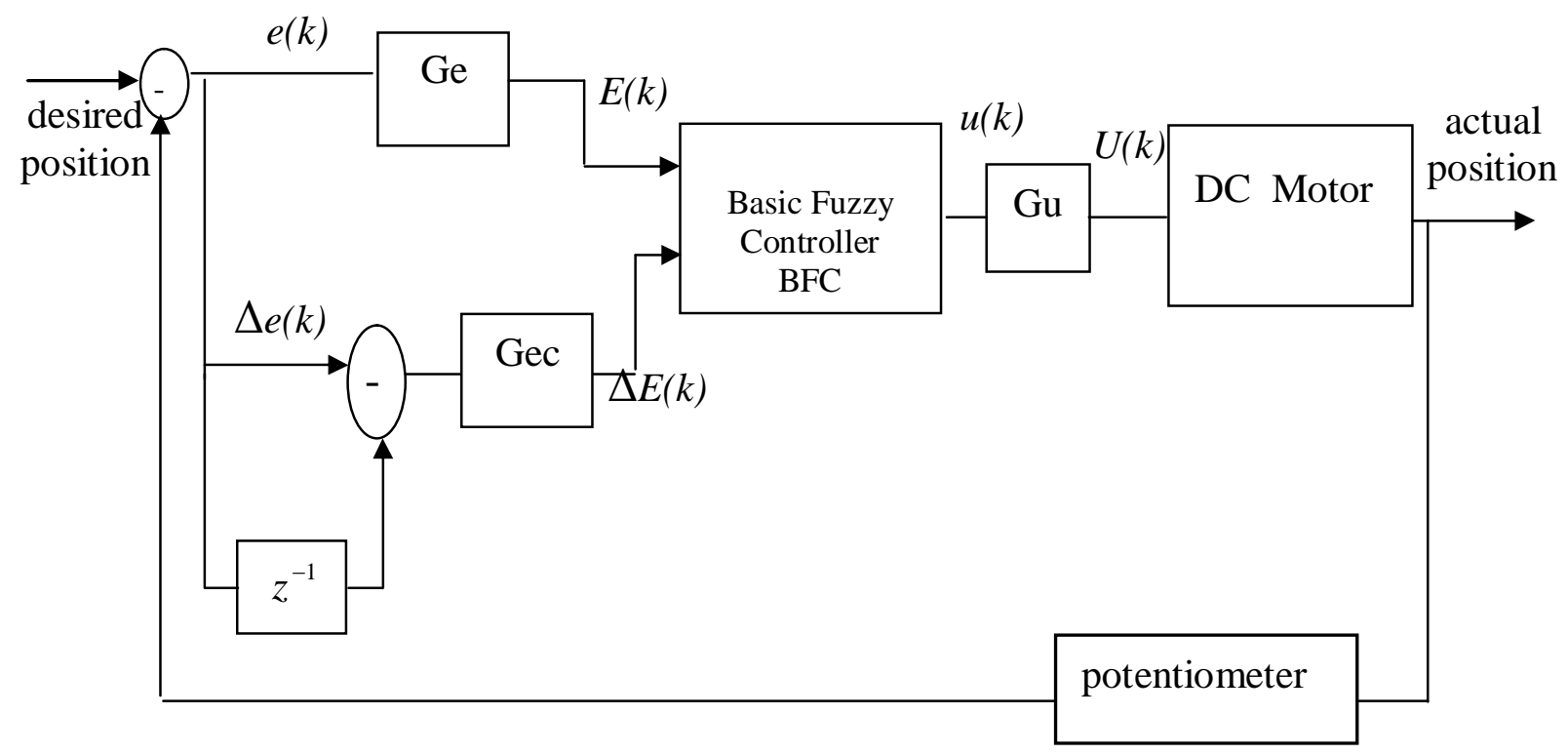

Figure 1: Block diagram of fixed factors fuzzy controller

The LabVIEW software is used to develop the VI-invironment which has two main parts, a front panel and a block diagram. The front panel is used for user interactions and display of results. The block diagram is the source code constructed using LabVIEW's graphical programming language. LabVIEW has a Fuzzy Logic Toolkit that enables users to integrate fuzzy logic control into virtual instruments. This toolkit is utilized in this current work to design and implement rule-based fuzzy logic system for process control or expert decision making. Any fuzzy logic controller (FLC) comprises four principal components fuzzification, inference engine, knowledge base, and defuzzification [10]. This is shown in Fig.2.

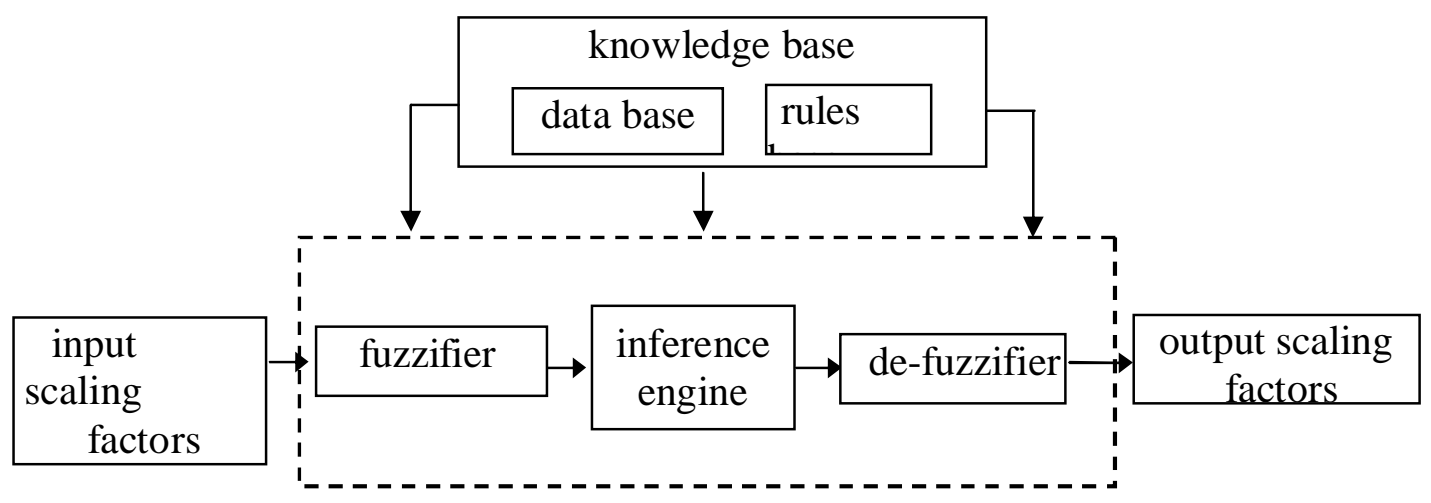

Figure 2: Components of the FLC and its I/O factors

Fuzzification block or the fuzzifier transforms crisp input to a linguistic variable, inference engine handles the rules to infer the output contributed from each rule, the knowledge base contains the rules that represent the control strategy of the system and data base to save information about the controller. The de-fuzzifier transforms back the computed output into crisp value. 


\section{Al-Rafidain Engineering $\quad$ Vol.17 No.4 $\quad$ August 2009}

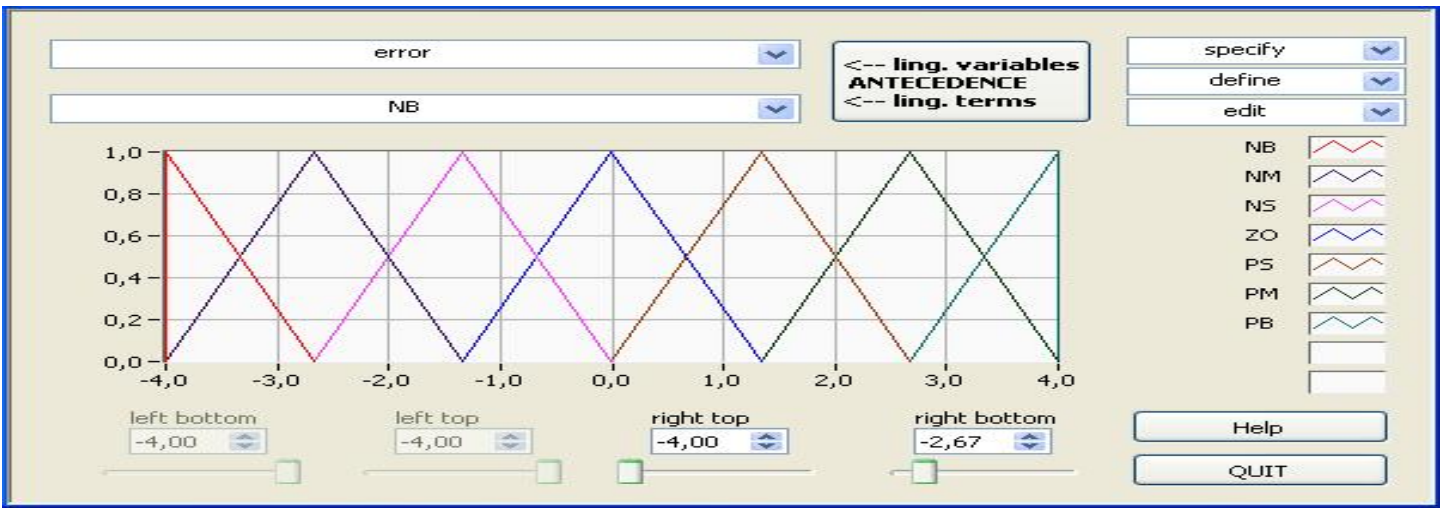

Figure 3: Membership functions of the inputs

The designed FLC (Fuzzy Logic Controller) is based on Mamdani fuzzy type [11], centre of gravity deffuzification method, Min - Max inference. Triangle membership functions are used to subdivide the input and output universe and to define the degree of membership. As shown in Fig. 3 and Fig. 4 there are seven states of the input position error (E), position error's change $(\Delta \mathrm{E})$, and the output of the controller $(\mathrm{u})$.

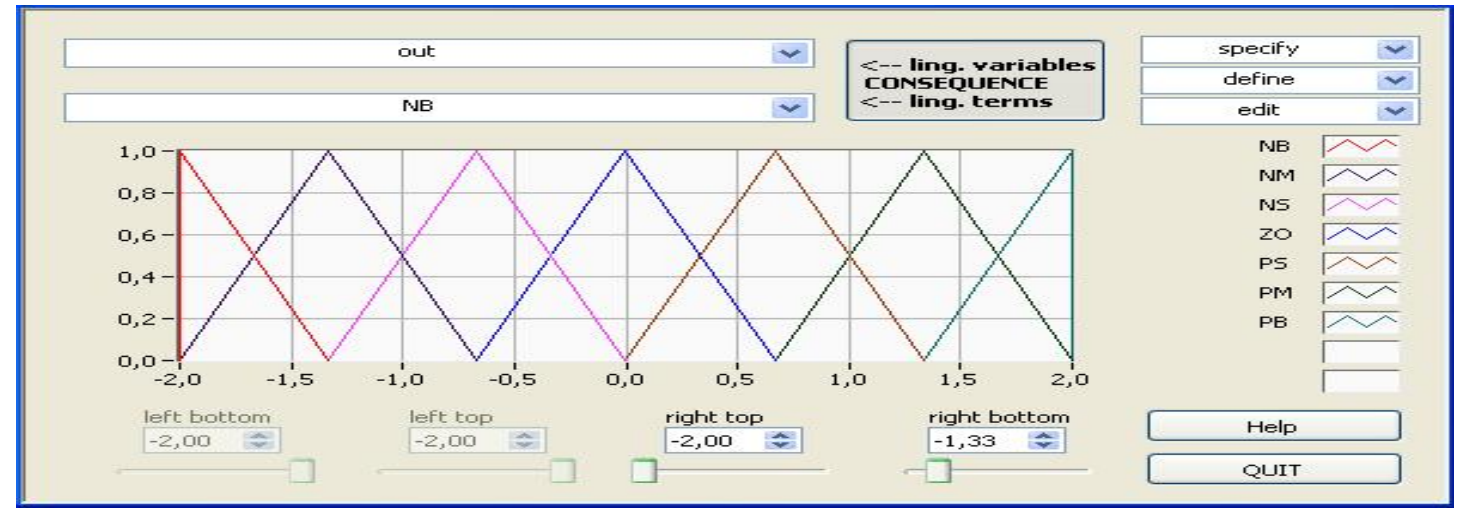

Figure 4: Output membership functions

From the experience of DC motor control we gain the fuzzy control rules shown in Table (1). The input factors Ge and Gec shown in Fig.1 are used to map the real measured variables from potentiometer into values in the UOD span before fuzzy reasoning. The controller crisp output (u) should be translated to the basic domain accepted by the DC Motor which is accomplished by the output factor $\mathrm{Gu}$.

Table 1: Fuzzy rules for the BFC

\begin{tabular}{||c|c|c|c|c|c|c|c||}
\hline $\mathbf{E}$ & NB & NM & NS & ZO & PS & PM & PB \\
\hline NB & NB & NB & NB & NM & NS & NS & ZO \\
\hline NM & NB & NM & NM & NM & NS & ZO & PS \\
\hline NS & NB & NM & NS & NS & ZO & PS & PM \\
\hline ZE & NB & NM & NS & ZO & PS & PM & PB \\
\hline PS & NM & NS & ZO & PS & PS & PM & PB \\
\hline PM & NS & ZO & PS & PM & PM & PM & PB \\
\hline PB & ZO & PS & PS & PM & PB & PB & PB \\
\hline
\end{tabular}




\section{3- Effect of I/O factors on the response of the controller}

Before the design of a self tuning controller, a study is necessary of the effect of these factors on the time domain characteristics of its response that reveals its performance. This step is considered the basis for the design of the supervisor fuzzy controllers.

\subsection{Effect of the input factors}

Input factors can be interpreted as the change of the UOD for input variables [4] which basically reduce the number of operating membership functions (and rules) because it pushes the marginal membership functions outside the firing zone therefore the adjusting of these factors is equivalent to reconstruction of the membership functions in the rule base since it will cause the antecedents of the fuzzy inference rules change after the fuzzification and this is why these factors can influence the overall performance of the FLC [12].

From the result shown in Fig.5 and Fig.6, it can be concluded that the effect of increasing the factor Ge is opposite to that of Gec. If Ge is increased the control of error is enhanced, as a result, the rise time is decreased and the settling time is decreased. However, a too large $\mathrm{Ge}$ will increase the overshoot and cause the convergence to slow down with even oscillation sometimes. These results are demonstrated in Fig. 5 which shows the response of a DC Motor where $\mathrm{Gec}$ and $\mathrm{Gu}$ remain constant but $\mathrm{Ge}$ is varied from 0.25 to 1 . On the other hand, the adjustment of Gec affects the control of error's change, so when Gec is decreased the rise time decreases which will speed the transient but a too small Gec will cause overshoot as demonstrated in Fig.6. Table (2) contains the parameters measured from these responses.

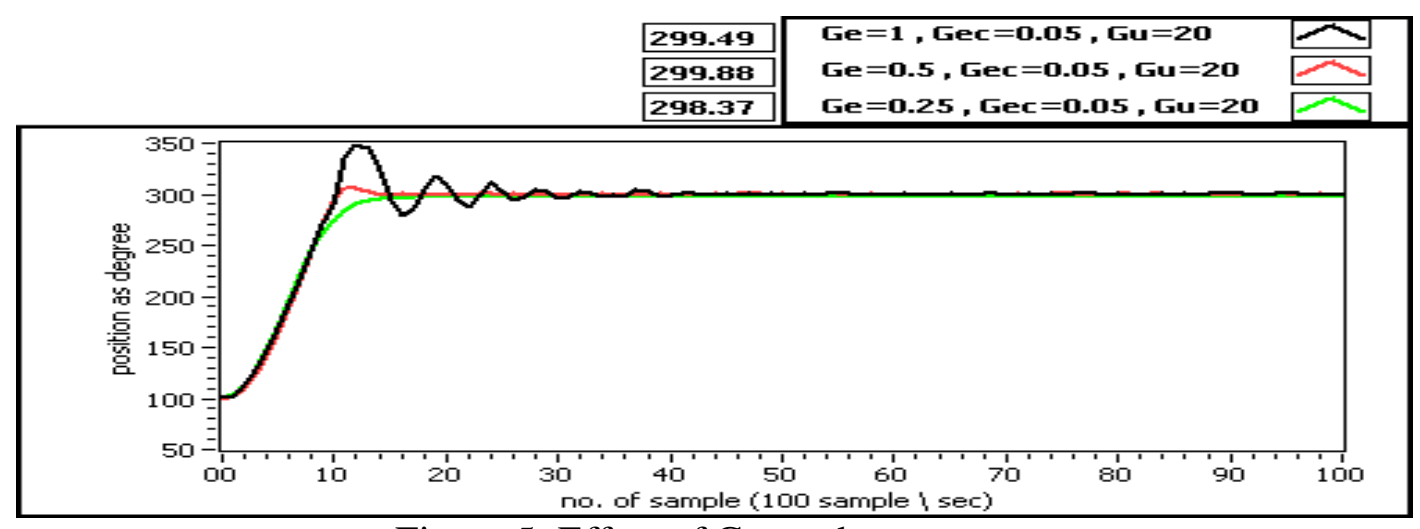

Figure 5: Effect of Ge on the response

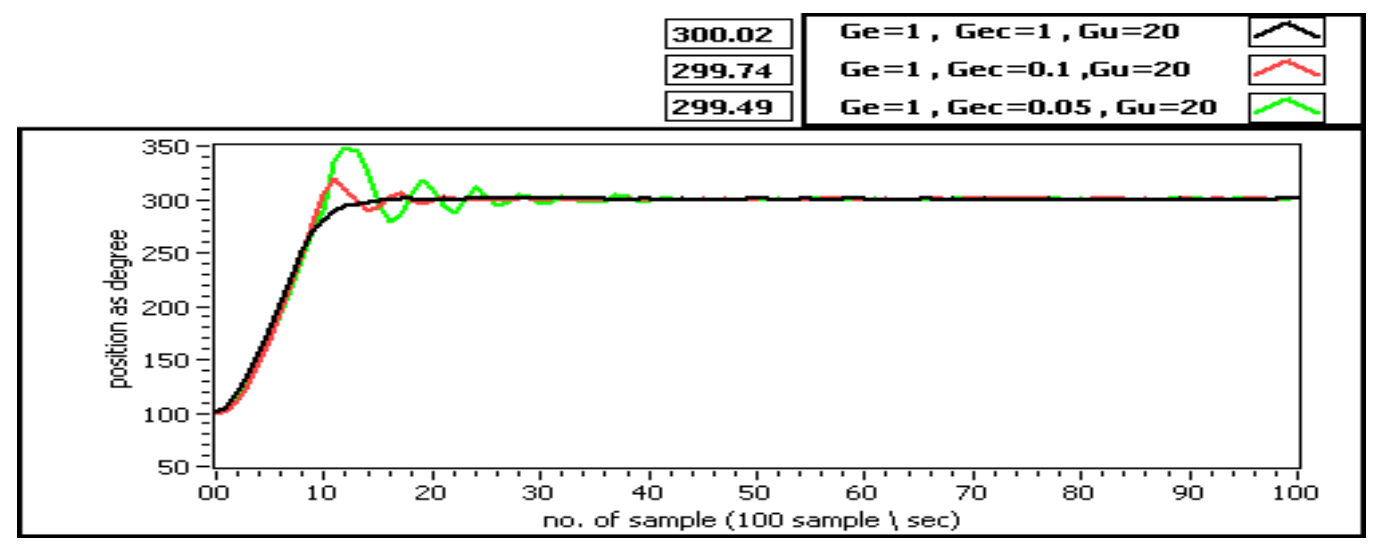

Figure 6: Effect of Gec on the response 


\section{Al-Rafidain Engineering $\quad$ Vol.17 $\quad$ No.4 $\quad$ August 2009}

Table 2: Results of effect of Ge and Gec on the response

\begin{tabular}{|l|c|c|c|c|c|c|}
\hline \multicolumn{1}{|c|}{ Parameter } & $\begin{array}{c}\% \\
\text { overshoot }\end{array}$ & $\begin{array}{c}\text { settling } \\
\text { time } \\
\text { (sec) }\end{array}$ & $\begin{array}{c}\text { rise } \\
\text { time } \\
(\mathbf{s e c})\end{array}$ & $\begin{array}{c}\text { peak } \\
\text { time } \\
(\mathbf{s e c})\end{array}$ & $\begin{array}{c}\text { peak } \\
\text { value }\end{array}$ & $\begin{array}{c}\text { s.s } \\
\text { error }\end{array}$ \\
\hline $\mathrm{Ge}=1, \mathrm{Gec}=0.05, \mathrm{Gu}=20$ & 24.582 & 0.24 & 0.07 & 0.1227 & $349.246^{\circ}$ & $0.510^{\circ}$ \\
\hline $\mathrm{Ge}=0.5, \mathrm{Gec}=0.05, \mathrm{Gu}=20$ & 3.5925 & 0.10 & 0.07 & 0.1147 & $307.065^{\circ}$ & $0.119^{\circ}$ \\
\hline $\mathrm{Ge}=0.25, \mathrm{Gec}=0.05, \mathrm{Gu}=20$ & 0000 & 0.12 & 0.08 & 0.1506 & $297.932^{\circ}$ & $1.628^{\circ}$ \\
\hline
\end{tabular}

\begin{tabular}{|l|c|c|c|c|c|c|}
\hline $\mathrm{Ge}=1, \mathrm{Gec}=1, \mathrm{Gu}=20$ & 0.164 & 0.11 & 0.07 & 0.1529 & $300.328^{\circ}$ & $0.021^{\circ}$ \\
\hline $\mathrm{Ge}=1, \mathrm{Gec}=0.1, \mathrm{Gu}=20$ & 9.958 & 0.14 & 0.07 & 0.1112 & $319.929^{\circ}$ & $0.259^{\circ}$ \\
\hline $\mathrm{Ge}=1, \mathrm{Gec}=0.05 \mathrm{Gu}=20$ & 24.582 & 0.24 & 0.07 & 0.1227 & $349.246^{\circ}$ & $0.510^{\circ}$ \\
\hline
\end{tabular}

\subsection{Effect of the output factor}

On the contrary of the case with Ge and Gec, the output factor $\mathrm{Gu}$ is the gain used to transfer $\mathrm{u}(\mathrm{k})$ to the actual output value which can directly be applied to the plant. Therefore the tuning of the output factor $\mathrm{Gu}$ is more important because of its direct influence on the performance and stability of the system. Actually, the change of the scaling factor $\mathrm{Gu}$ expands or contracts the membership functions similar to how an accordion operates[7]. If the $\mathrm{Gu}$ increases, the UOD of Gu will extend and the actual value of the output of the controller will increase too, and thus the controller will execute stronger actions to the plant making it respond more quickly as shown in Fig.7. A too large Gu may cause overshoot and oscillation. On the other hand decreasing $\mathrm{Gu}$ is beneficial to the stability of the system but it makes the transient response slower. Table(3) shows the parameters computed from Fig.7.

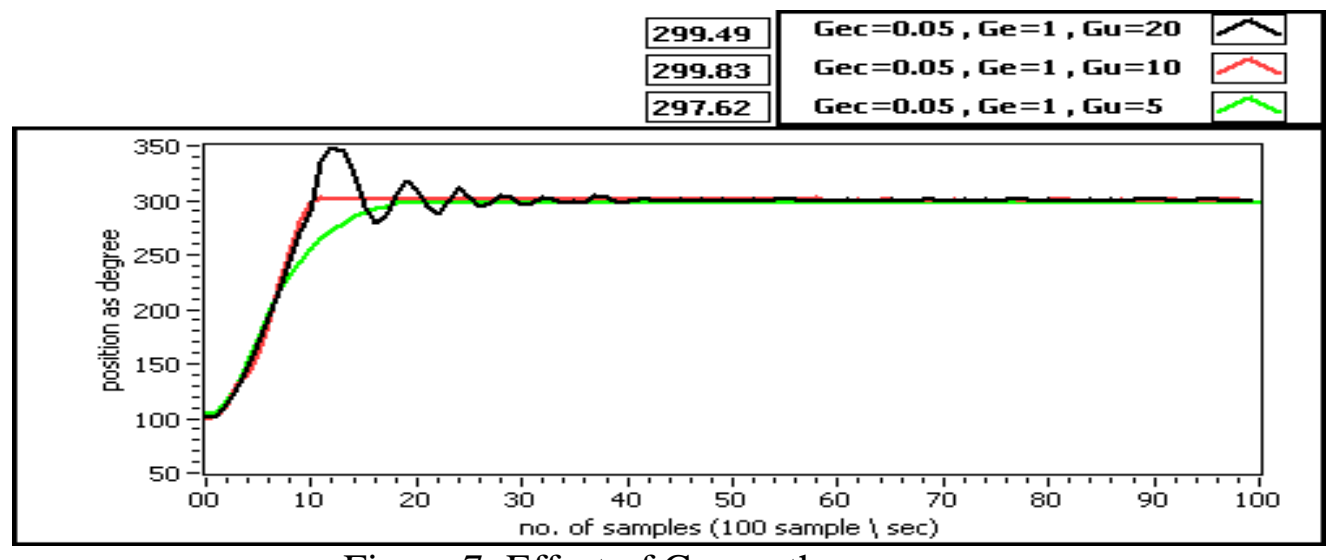

Figure 7: Effect of $\mathrm{Gu}$ on the response

Table 3: Results of effect of $\mathrm{Gu}$ on the response

\begin{tabular}{|c|c|c|c|c|c|c|}
\hline Parameter & $\begin{array}{c}\text { \% over- } \\
\text { shoot }\end{array}$ & $\begin{array}{c}\text { settlin } \\
\text { g time } \\
(\mathbf{s e c})\end{array}$ & $\begin{array}{c}\text { rise } \\
\text { time } \\
(\mathbf{s e c})\end{array}$ & $\begin{array}{c}\text { peak } \\
\text { time } \\
(\mathbf{s e c})\end{array}$ & $\begin{array}{c}\text { peak } \\
\text { value }\end{array}$ & $\begin{array}{c}\text { s.s } \\
\text { error }\end{array}$ \\
\hline $\mathrm{Gec}=0.05, \mathrm{Ge}=1, \mathrm{Gu}=20$ & 24.582 & 0.24 & 0.07 & 0.1227 & $349.246^{\circ}$ & $0.510^{\circ}$ \\
\hline $\mathrm{Gec}=0.05, \mathrm{Ge}=1, \mathrm{Gu}=10$ & 2.7275 & 0.10 & 0.07 & 0.1147 & $305.554^{\circ}$ & $0.114^{\circ}$ \\
\hline $\mathrm{Gec}=0.05, \mathrm{Ge}=1, \mathrm{Gu}=5$ & 0000 & 0.15 & 0.11 & 0.1834 & $298.069^{\circ}$ & $2.383^{\circ}$ \\
\hline
\end{tabular}


From the previous analysis we can conclude that the I/O factors do have strong effects on the performance of the controller, especially the output scaling factor $\mathrm{Gu}$. It must also be mentioned that the results above are taken for one state when moving from position $100^{\circ}$ to $300^{\circ}$ but on other positions the best values of these factors could be altered. On the other hand, the optimum set values of the three factors dose not necessitate the optimum value of each individual one. This is why this problem needs adaptive mechanism, the fuzzy control systems with fixed parameters are non-adaptive. Therefore tuning of these factors according to actual error $\mathrm{E}$ and change of error $\Delta \mathrm{E}$ on-line and in different periods of transient response is necessary to make the BFC adaptive controller. The proposed scheme, to accomplish this goal, is demonstrated in the next section.

\section{Design of a self-tuning FLC}

Since the variables and their state are linguistic values (like: IF Gec decreases, the overshoot increases), they can only be interpreted qualitatively and inexactly.Therefore a technique is needed to describe these vague values. Fuzzy set is one of the perfect tools to process the linguistic information. So another level of fuzzy controllers is added to adjust the I/O factors on-line. The structure of the proposed controller is shown in Fig. 8. The supervisor fuzzy controllers represent three controllers each for one of the three gains $\mathrm{Ge}, \mathrm{Gec}$, and $\mathrm{Gu}$ for adjusting these factors according to the position error and change of position error, at each sample, according to the following equations:

$\mathrm{E}(\mathrm{k})=\mathrm{Ge}(\mathrm{k}) \mathrm{e}(\mathrm{k})$

$\Delta \mathrm{E}(\mathrm{k})=\mathrm{Gec}(\mathrm{k}) \Delta \mathrm{e}(\mathrm{k})$

$\mathrm{U}(\mathrm{k})=\mathrm{F}(\mathrm{E}(\mathrm{k}), \Delta \mathrm{E}(\mathrm{k})) \mathrm{Gu}(\mathrm{k})$

$\mathrm{U}(\mathrm{k})=\mathrm{F}(\mathrm{Ge}(\mathrm{k}) \mathrm{e}(\mathrm{k}), \mathrm{Gec}(\mathrm{k}) \Delta \mathrm{e}(\mathrm{k})) \mathrm{Gu}(\mathrm{k})$

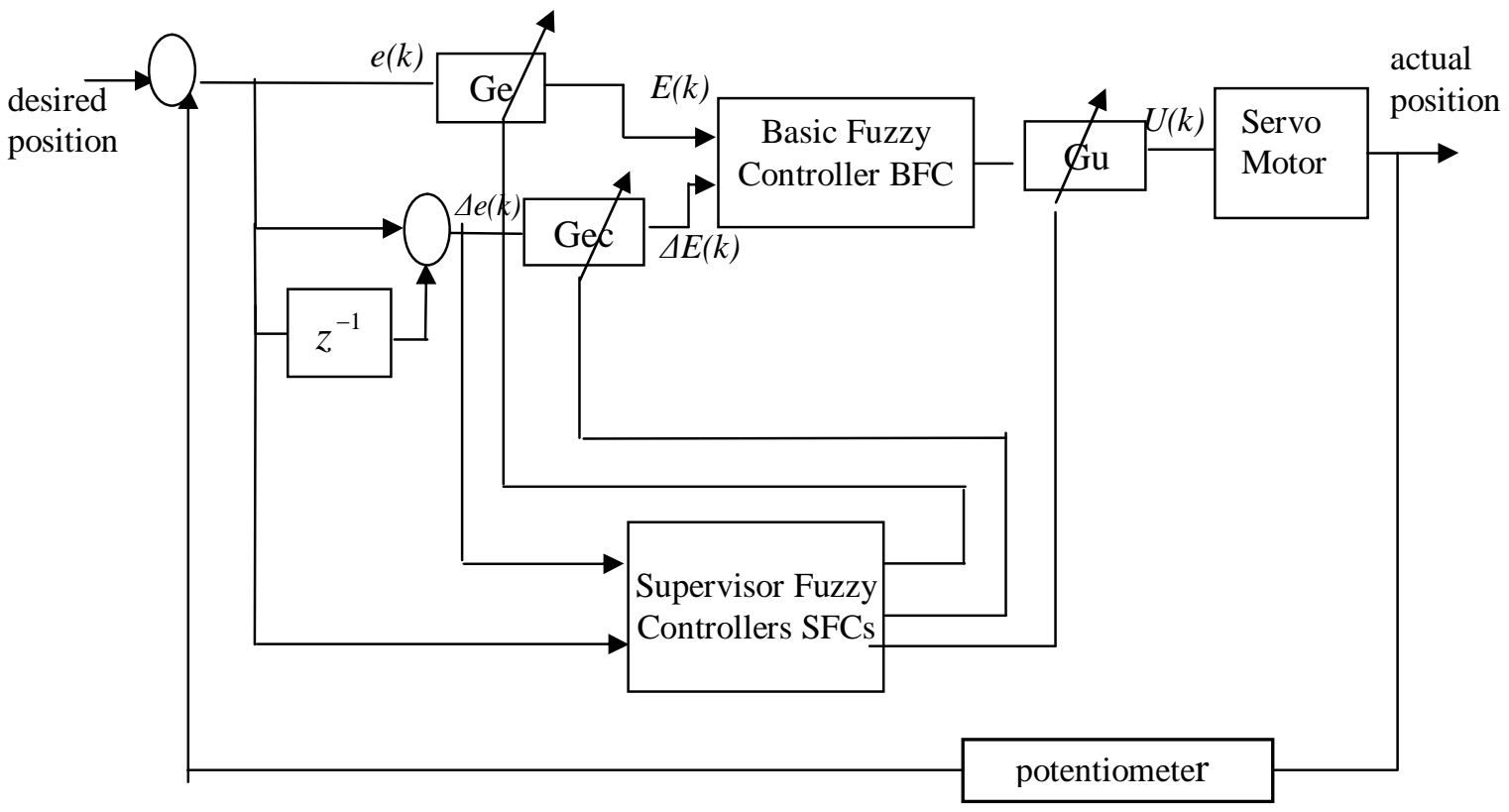

Figure 8: Structure of the proposed self-tuning FLC 


\section{$\begin{array}{llll}\text { Al-Rafidain Engineering } & \text { Vol.17 } & \text { No.4 } & \text { August } 2009\end{array}$}

Table 2: Rule base for Ge

\begin{tabular}{||c|c|c|c|c|c|c|c||}
\hline$\Delta \mathrm{E}$ & $\mathrm{NB}$ & $\mathrm{NM}$ & $\mathrm{NS}$ & $\mathrm{ZO}$ & $\mathrm{PS}$ & $\mathrm{PM}$ & $\mathrm{PB}$ \\
\hline $\mathrm{NB}$ & $\mathrm{VB}$ & $\mathrm{VB}$ & $\mathrm{S}$ & $\mathrm{S}$ & $\mathrm{M}$ & $\mathrm{B}$ & $\mathrm{B}$ \\
\hline $\mathrm{NM}$ & $\mathrm{VB}$ & $\mathrm{VB}$ & $\mathrm{S}$ & $\mathrm{S}$ & $\mathrm{S}$ & $\mathrm{M}$ & $\mathrm{VB}$ \\
\hline $\mathrm{NS}$ & $\mathrm{VB}$ & $\mathrm{VB}$ & $\mathrm{VS}$ & $\mathrm{M}$ & $\mathrm{VS}$ & $\mathrm{VB}$ & $\mathrm{VB}$ \\
\hline $\mathrm{ZO}$ & $\mathrm{VB}$ & $\mathrm{B}$ & $\mathrm{VS}$ & $\mathrm{M}$ & $\mathrm{VS}$ & $\mathrm{VB}$ & $\mathrm{VB}$ \\
\hline $\mathrm{PS}$ & $\mathrm{VB}$ & $\mathrm{M}$ & $\mathrm{VS}$ & $\mathrm{M}$ & $\mathrm{VS}$ & $\mathrm{VB}$ & $\mathrm{VB}$ \\
\hline $\mathrm{PM}$ & $\mathrm{B}$ & $\mathrm{B}$ & $\mathrm{S}$ & $\mathrm{S}$ & $\mathrm{S}$ & $\mathrm{M}$ & $\mathrm{VB}$ \\
\hline PB & B & B & S & S & S & B & B \\
\hline
\end{tabular}

From formula (7) it is clear that the three factors of fuzzy controllers have effect on the output characteristics of the system. However the value of each factor is computed in real time according to the control rules that are extracted directly from the experiences mentioned before and the control knowledge outcome from different response periods. These rules are listed in Tables 2, 3, and 4 for Ge, Gec, and Gu respectively. The VI-pictorial block diagram of the system is shown in Fig. 9.

Table 3: Rule base for Gec

\begin{tabular}{||c|c|c|c|c|c|c|c||}
\hline$\Delta \mathrm{E}$ & $\mathrm{NB}$ & $\mathrm{NM}$ & $\mathrm{NS}$ & $\mathrm{ZO}$ & $\mathrm{PS}$ & $\mathrm{PM}$ & $\mathrm{PB}$ \\
\hline $\mathrm{NB}$ & $\mathrm{VB}$ & $\mathrm{VB}$ & $\mathrm{VB}$ & $\mathrm{VS}$ & $\mathrm{VS}$ & $\mathrm{VS}$ & $\mathrm{S}$ \\
\hline $\mathrm{NM}$ & $\mathrm{VB}$ & $\mathrm{VB}$ & $\mathrm{VB}$ & $\mathrm{VS}$ & $\mathrm{VS}$ & $\mathrm{VS}$ & $\mathrm{S}$ \\
\hline $\mathrm{NS}$ & $\mathrm{VB}$ & $\mathrm{B}$ & $\mathrm{B}$ & $\mathrm{M}$ & $\mathrm{S}$ & $\mathrm{S}$ & $\mathrm{VS}$ \\
\hline $\mathrm{ZO}$ & $\mathrm{VB}$ & $\mathrm{B}$ & $\mathrm{B}$ & $\mathrm{M}$ & $\mathrm{VS}$ & $\mathrm{S}$ & $\mathrm{VS}$ \\
\hline $\mathrm{PS}$ & $\mathrm{B}$ & $\mathrm{S}$ & $\mathrm{S}$ & $\mathrm{M}$ & $\mathrm{B}$ & $\mathrm{B}$ & $\mathrm{VB}$ \\
\hline $\mathrm{PM}$ & $\mathrm{S}$ & $\mathrm{S}$ & $\mathrm{VS}$ & $\mathrm{VS}$ & $\mathrm{B}$ & $\mathrm{VB}$ & $\mathrm{VB}$ \\
\hline $\mathrm{PB}$ & $\mathrm{S}$ & $\mathrm{VS}$ & $\mathrm{VS}$ & $\mathrm{VS}$ & $\mathrm{B}$ & $\mathrm{VB}$ & $\mathrm{VB}$ \\
\hline
\end{tabular}

Table 4: Rule base for Gu factor

\begin{tabular}{||c|c|c|c|c|c|c|c||}
\hline$\Delta E$ & NB & NM & NS & ZO & PS & PM & PB \\
\hline NB & VB & VB & VB & B & SB & S & ZO \\
\hline NM & VB & VB & B & B & MB & S & VS \\
\hline NS & VB & MB & B & VB & VS & S & VS \\
\hline ZO & S & SB & MB & ZO & MB & SB & S \\
\hline PS & VS & S & VS & VB & B & MB & VB \\
\hline PM & VS & S & MB & B & B & VB & VB \\
\hline PB & ZO & S & SB & B & VB & VB & VB \\
\hline
\end{tabular}




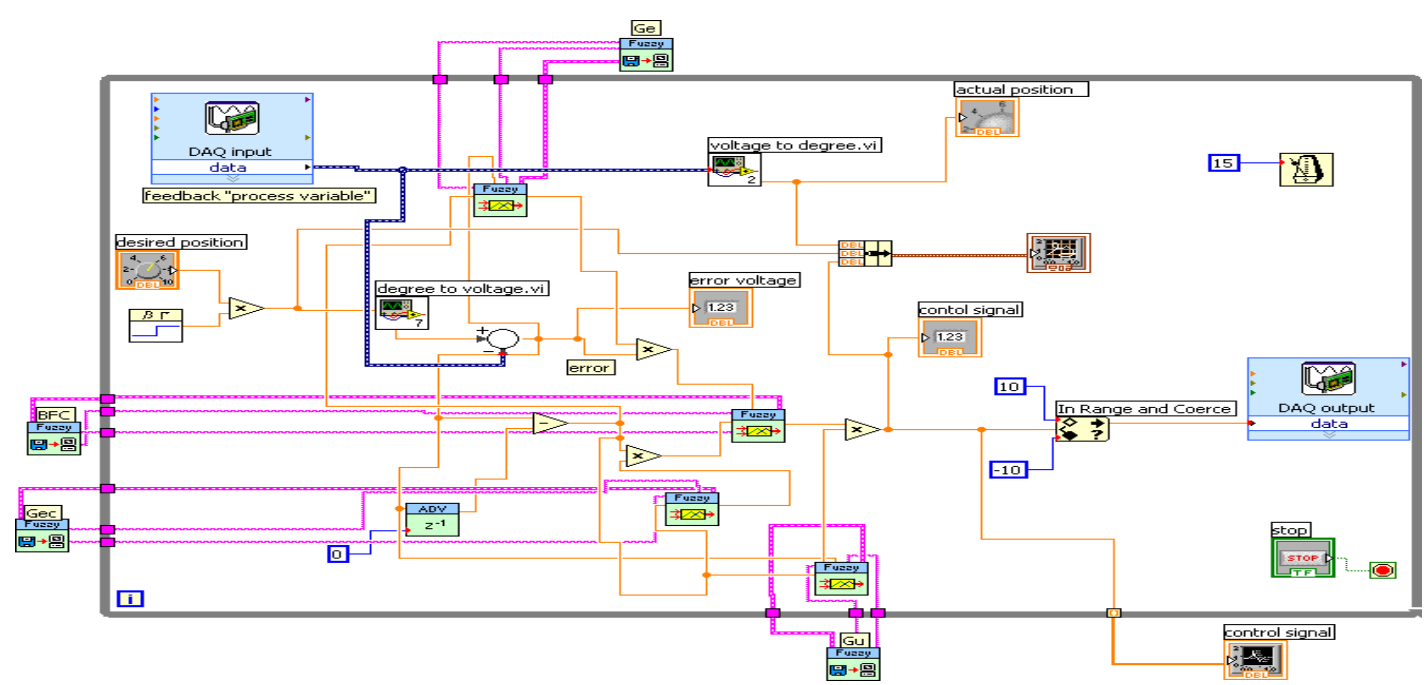

Figure 9: VI-Block diagram of the proposed system

\section{Test results}

The proposed controller has been successfully applied to control a DC Motor. To evaluate the controller performance, several position tracks are applied and the controller is tested and the results are presented in Fig.10, 11, and 12 for the performance comparison between self tuning factors and fixed factors fuzzy control actions.

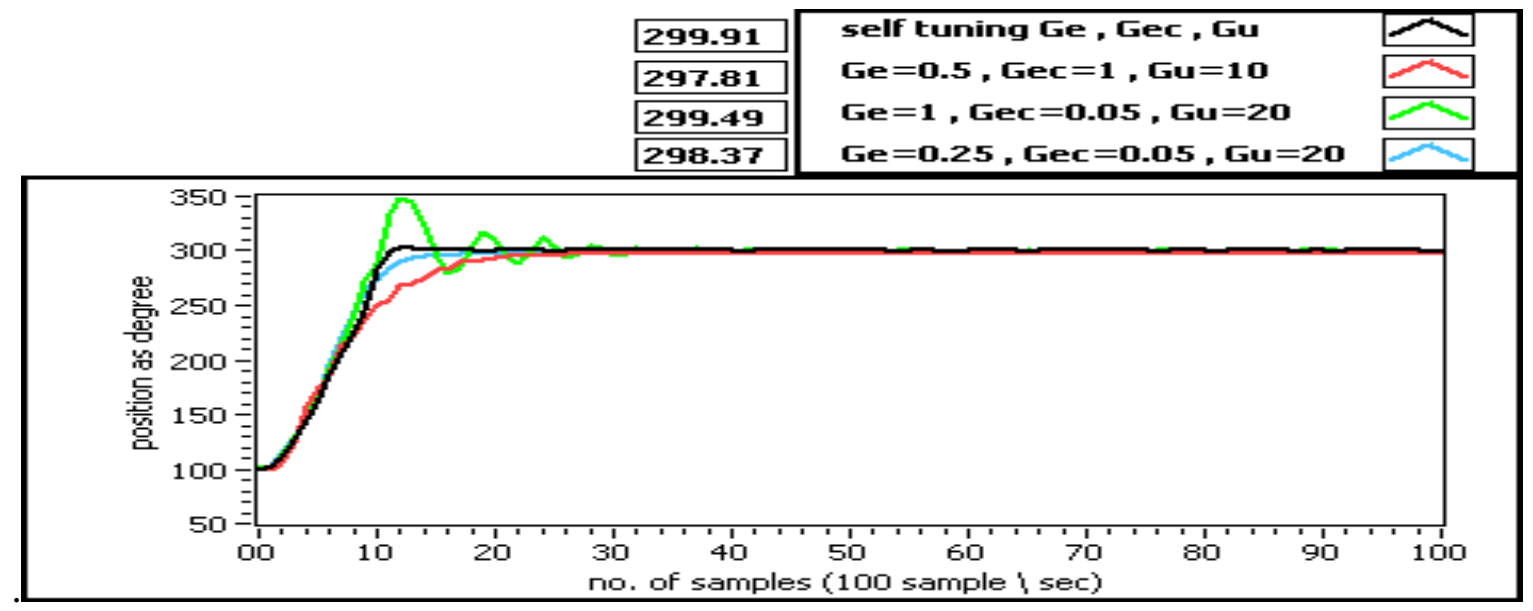

Figure 10: Control tracking response for a step from $100^{\circ}$ to $300^{\circ}$

Table 5: Response parameters of figure 10

\begin{tabular}{|l|c|c|c|c|c|c|}
\hline \multicolumn{1}{|c|}{ Position: $100^{\circ} \rightarrow 300^{\circ}$} & $\begin{array}{c}\% \\
\text { overshoot }\end{array}$ & $\begin{array}{c}\text { settling } \\
\text { time } \\
\text { (sec) }\end{array}$ & $\begin{array}{c}\text { rise } \\
\text { time } \\
\text { (sec) }\end{array}$ & $\begin{array}{c}\text { peak } \\
\text { time } \\
\text { (sec) }\end{array}$ & $\begin{array}{c}\text { peak } \\
\text { value }\end{array}$ & $\begin{array}{c}\text { s.s } \\
\text { error }\end{array}$ \\
\hline Self tuning Gec $, \mathrm{Ge}, \mathrm{Gu}$ & 1.5625 & 0.11 & 0.07 & 0.1258 & $303.125^{\circ}$ & $0.09^{\circ}$ \\
\hline $\mathrm{Ge}=0.5, \mathrm{Gec}=1, \mathrm{Gu}=10$ & 0000 & 0.17 & 0.12 & 0.2385 & $296.036^{\circ}$ & $2.187^{\circ}$ \\
\hline $\mathrm{Ge}=1, \mathrm{Gec}=0.05, \mathrm{Gu}=20$ & 24.582 & 0.24 & 0.07 & 0.1227 & $349.246^{\circ}$ & $0.510^{\circ}$ \\
\hline $\mathrm{Ge}=0.25, \mathrm{Gec}=0.05, \mathrm{Gu}=20$ & 0000 & 0.12 & 0.08 & 0.1506 & $297.932^{\circ}$ & $1.628^{\circ}$ \\
\hline
\end{tabular}




\section{$\begin{array}{llll}\text { Al-Rafidain Engineering } & \text { Vol.17 } & \text { No.4 } & \text { August } 2009\end{array}$}

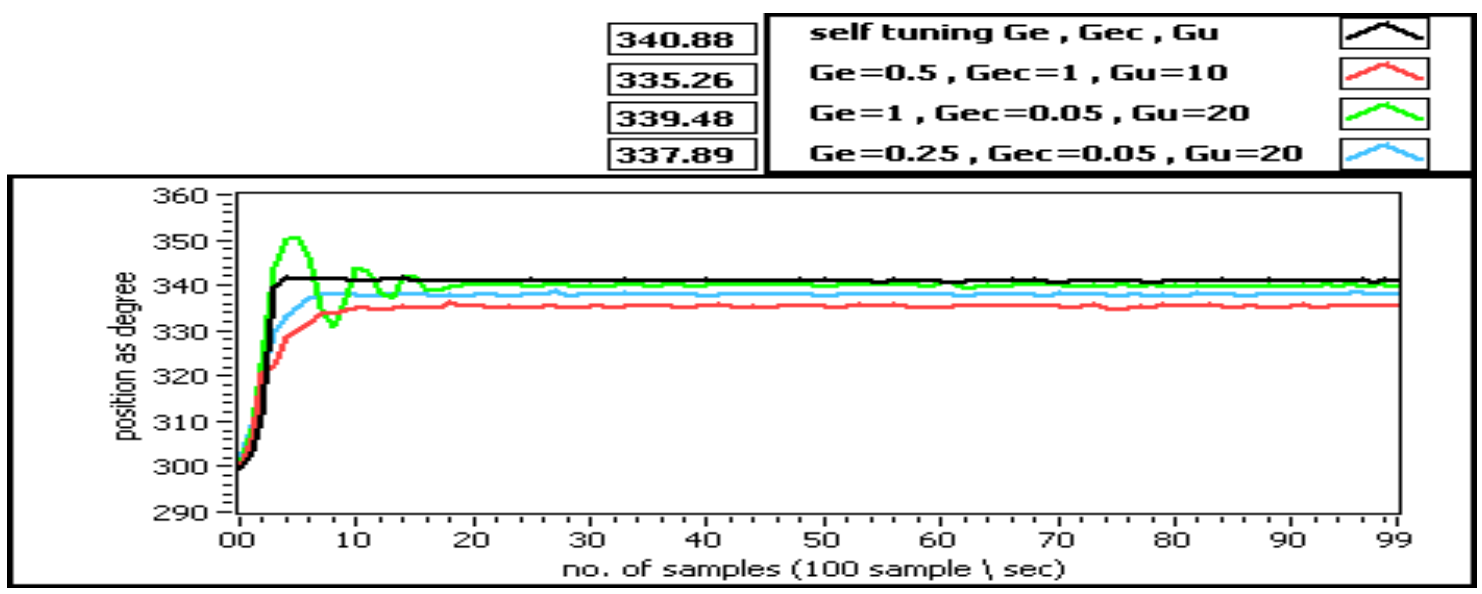

Figure 11: Control tracking response for a step from $300^{\circ}$ to $340^{\circ}$

Table 6: Response parameters of figure 11

\begin{tabular}{|l|c|c|c|c|c|c|}
\hline Position: $300^{\circ} \rightarrow 340^{\circ}$ & $\begin{array}{c}\% \\
\text { overshoot }\end{array}$ & $\begin{array}{c}\text { settling } \\
\text { time } \\
\text { (sec) }\end{array}$ & $\begin{array}{c}\text { rise } \\
\text { time } \\
\text { (sec) }\end{array}$ & $\begin{array}{c}\text { peak } \\
\text { time } \\
\text { (sec) }\end{array}$ & $\begin{array}{c}\text { peak } \\
\text { value }\end{array}$ & $\begin{array}{c}\text { s.s } \\
\text { error }\end{array}$ \\
\hline Self tuning Gu, Ge, Gec & 1.995 & 0.03 & 0.01 & 0.0439 & $341.653^{\circ}$ & $0.879^{\circ}$ \\
\hline $\mathrm{Ge}=0.5, \mathrm{Gec}=1, \mathrm{Gu}=10$ & 0000 & 1.00 & 0.17 & 0.1081 & $335.139^{\circ}$ & $4.738^{\circ}$ \\
\hline $\mathrm{Ge}=1, \mathrm{Gec}=0.05, \mathrm{Gu}=20$ & 26.577 & 0.18 & 0.02 & 0.045 & $351.070^{\circ}$ & $0.238^{\circ}$ \\
\hline $\mathrm{Ge}=0.25, \mathrm{Gec}=0.05, \mathrm{Gu}=20$ & 1.812 & 1.00 & 0.05 & 0.075 & $337.837^{\circ}$ & $2.110^{\circ}$ \\
\hline
\end{tabular}

The first fixed factors group is set to $\mathrm{Ge}=0.5$ from Fig. (5), $\mathrm{Gec}=1$ from Fig. (6), and $\mathrm{Gu}=10$ from Fig. (7). The other fixed factors are set by selecting the best group values obtained by hand tuning. The parameters computed from these three figures are tabulated in tables 5, 6, and 7 respectively.

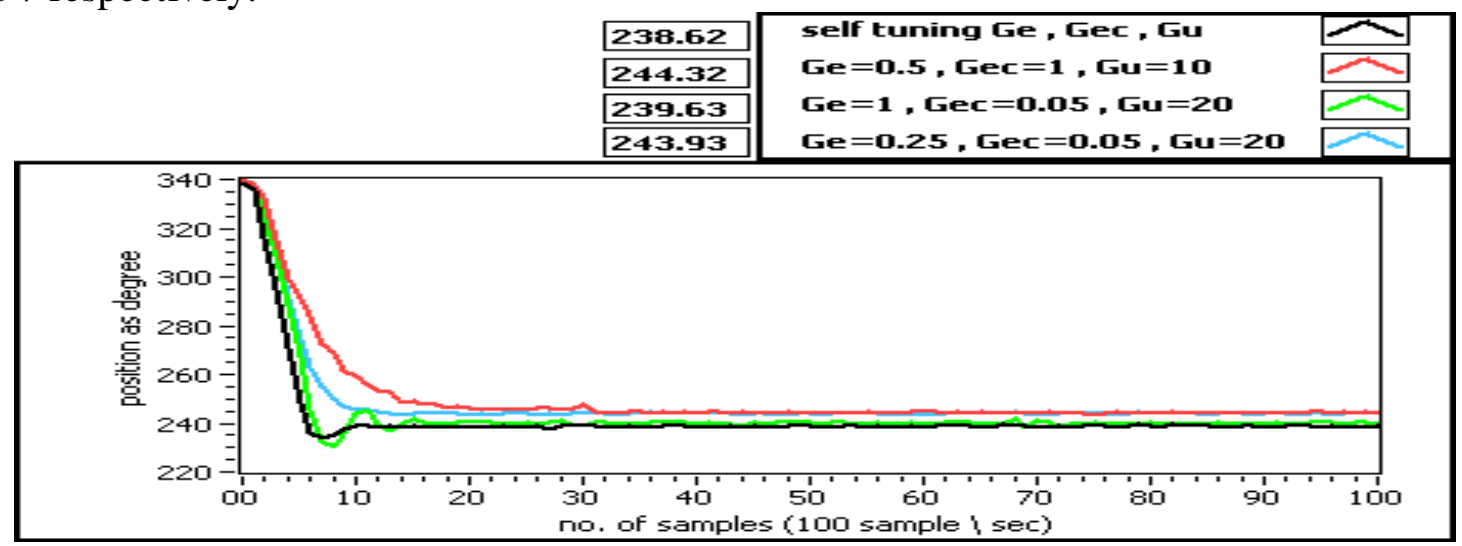

Figure 12: Control tracking response for a step from $340^{\circ}$ to $240^{\circ}$

Table 7: Response parameters of figure 12

\begin{tabular}{|l|c|c|c|c|c|c|}
\hline \multicolumn{1}{|c|}{ Position: $340^{\circ} \rightarrow 240^{\circ}$} & $\begin{array}{c}\% \\
\text { over- } \\
\text { shoot }\end{array}$ & $\begin{array}{c}\text { Settling } \\
\text { time } \\
\text { (sec) }\end{array}$ & $\begin{array}{c}\text { rise } \\
\text { time } \\
(\mathbf{s e c})\end{array}$ & $\begin{array}{c}\text { peak } \\
\text { time } \\
\text { (sec) }\end{array}$ & $\begin{array}{c}\text { peak } \\
\text { value }\end{array}$ & $\begin{array}{c}\text { s.s } \\
\text { error }\end{array}$ \\
\hline Self tuning Gu, Ge, $\mathrm{Gec}$ & 5.178 & 0.07 & 0.03 & 0.0734 & $233.506^{\circ}$ & $1.379^{\circ}$ \\
\hline $\mathrm{Ge}=0.5, \mathrm{Gec}=1, \mathrm{Gu}=10$ & 0000 & 0.13 & 0.11 & 0.1367 & $248.682^{\circ}$ & $4.322^{\circ}$ \\
\hline $\mathrm{Ge}=1, \mathrm{Gec}=0.05, \mathrm{Gu}=20$ & 9.998 & 0.11 & 0.04 & 0.0802 & $230.041^{\circ}$ & $0.373^{\circ}$ \\
\hline $\mathrm{Ge}=0.25, \mathrm{Gec}=0.05, \mathrm{Gu}=20$ & 0000 & 1.00 & 0.06 & 0.1412 & $243.595^{\circ}$ & $3.931^{\circ}$ \\
\hline
\end{tabular}




\section{Conclusions}

In this paper, a self-tuning fuzzy logic controller with on-line variable I/O factors using fuzzy inference rules is implemented based on LabVIEW. The test results on a real plant DC motor, with unknown parameters, show that the proposed controller has an improved performance compared with fixed factors fuzzy controller. On-line self tuning of all factors at the same time proved to be necessary to achieve the best parameters set-values of over shoot, transient response time, and steady state error. This is justified by both the response figures $(10,11,12)$ and the response parameters tables $(5,6,7)$. Since the step response tests of the proposed control scheme are carried out in real time, it is proved to be practical and adaptive.

\section{References}

[1] Xinxin Y. and Lei Y. , Kezhong H. , Shengle H. , Muhe G. , Bo Z. " A Double-Level Fuzzy Controller with an Intelligently Adjusting Strategy of Quantization and Scale Factors " IEEE trans. , P.280-285 vol.1 , 14-17Oct , 1996 .

[2] Cirstea M.N. , Dinu A. , Khor J.G. , McCormick M. " Neural and Fuzzy Logic Control of Drives and Power Systems" M.N. Cirstea, A. Dinu, J.G. Khor, M. McCormick, ISBN 0 7506 55585., 2002.

[3] Rajani K. Mudi and Nikhil R. " A Robust Self-Tuning Scheme for PI- and PD-Type Fuzzy Controllers", IEEE Transactions on Fuzzy Systems, Vol. 7, No. 1, February 1999.

[4] Chen Y. , Perng, C. "Input Scaling Factors in Fuzzy Control Systems" , IEEE World Congress on Computational Intelligence , Fuzzy Systems, Pages: 1666 - 1670 vol.3 , 26-29 Jun 1994.

[5] Yongpan C. ,Jili Z. ,Bin Z. and Fusheng G., "Development of Monitoring Control and Fuzzy Control Test of Finned-Tube Heat-Exchanger Test Board " Building Commissioning for Energy Efficiency and Comfort, ICEBO shenzhen ,China Vol. VI-6-1 , 2006.

[6] Wang Y. and Deng H. "An Adaptive Fuzzy Logic Controller with Self-Tuning Scaling Factors Based on Neural Networks" IEEE Autonomous Decentralized Systems, ISADS. Pages: 392 - 396. Proceedings 4-8 April 2005.

[7] Jiangqiang H. , Tieshan L. and Chen G. , "Design of GA-Based Fuzzy Control for Ship Steering" Intelligent Control and Automation, The $6^{\text {th }}$. World Congress Vol 1, Pages: $3594-$ $3598,2006$.

[8] Jovitha J., Aravind A. P. , Arunkumar V. Balasubramanian P. "LabVIEW based Intellegent for Speed Regulation of Electric Motor " IEEE Transactions, Instrumentation and Measurement Technology Conf., IMTC. Vol 2, Issue , Pages: 935 - 940, 16-19 May 2005.

[9] National Instruments Co. "Introduction to LabVIEW", Austin (USA), 2003

[10] National Instruments Co., "PID Control Toolset User Manual ,Part II Fuzzy Logic Control", Part Number 322192A-01 Austin (USA), November 2001.

[11] Passino K. M. and Yurkovich S. , " Fuzzy Control " , Addision Wesley Longman, Inc., California. ISBN: 0-201-18074-x, 1998.

[12] Andri R. "Transparent Fuzzy Systems: Modeling and Control" Ph.D Dissertation , Tallinn Technical University, Dept. of Computer Control, Estonia , 2002. 